\title{
Cardioprotective Effects of Lowering Oxygen Tension After Aortic Unclamping on Cardiopulmonary Bypass During Coronary Artery Bypass Grafting
}

\author{
Takehiro Inoue, MD; Kwansong Ku, MD; Toshio Kaneda, MD; \\ Zhiwei Zang, MD; Masaki Otaki, MD; Hidetaka Oku, MD
}

\begin{abstract}
The effect on myocardial reperfusion injury of reducing oxygen tension during reperfusion on cardiopulmonary bypass $(\mathrm{CPB})$ in coronary artery bypass grafting $(\mathrm{CABG})$ was examined at the same time as the influence of diltiazem during $\mathrm{CPB}$ was evaluated. A prospective, randomized trial evaluated the hemodynamic and myocardial metabolic recovery in 3 groups of patients undergoing elective CABG; subjects were randomly allocated on the basis of oxygen tension during reperfusion after aortic unclamping: group $1(n=10)$ hyperoxic reperfusion (oxygen tension $\left[\mathrm{PO}_{2}\right]=450-550 \mathrm{mmHg}$ ); group $2(\mathrm{n}=10)$ : hyperoxic reperfusion and subsequent continuous infusion of diltiazem $(0.5 \mu \mathrm{g} / \mathrm{kg})$; group $3(\mathrm{n}=10)$ : lowering reperfusate $\mathrm{PO}_{2}\left(\mathrm{PO}_{2}=200-250 \mathrm{mmHg}\right)$. Hemodynamic and myocardial metabolic measurements were taken at 6 preset times: before starting the surgical procedure and at $30 \mathrm{~min}$ and 3,9,21, and $45 \mathrm{~h}$ after discontinuation of CPB. The cardiac index in the lowering reperfusate $\mathrm{PO}_{2}$ group was higher than that of the hyperoxic reperfusion groups at $30 \mathrm{~min}$ and $3 \mathrm{~h}$ after $\mathrm{CPB}$, and malondialdehyde and troponin-T were significantly lower at $30 \mathrm{~min}$ and $3 \mathrm{~h}$, respectively. In comparison with the hyperoxic + diltiazem group, the hemodynamic and myocardial recovery in the lowering reperfusate $\mathrm{PO}_{2}$ group was improved for about $3 \mathrm{~h}$ after $\mathrm{CPB}$. Reduced oxygen tension during reperfusion after aortic unclamping on $\mathrm{CPB}$ is more effective against myocardial injury than a calcium antagonist in the short term. It is a convenient and safe management technique that can reduce morbidity and mortality, especially in the severely compromised heart. (Circ J 2002; 66: 718-722)
\end{abstract}

Key Words: Cardiopulmonary bypass; Coronary artery bypass grafting; Oxygen tension

D espite the known reperfusion injury from oxygenderived free radicals and calcium overload, cardiopulmonary bypass $(\mathrm{CPB})$ during cardiac surgery is routinely hyperoxic! ? $^{-3}$ Because the rate of production of reactive oxygen-derived free radicals depends on the oxygen tension $\left(\mathrm{PO}_{2}\right)^{4,5}$ reperfusion injury could be reduced by lowering the tension instead of using antioxidants during extracorporeal circulation6 Ihnken et al reported that reducing the oxygen concentration in the $\mathrm{CPB}$ circuit to 'normoxic' levels reduces the damaging effects of hyperoxia? On the other hand, calcium antagonists improve myocardial recovery after ischemia-reperfusion, 8 although they do have negative inotropic side effects. Of the calcium antagonists, diltiazem has cardioprotective effects in experimental as well as clinical settings $!^{10,11}$

In the present study, we examined the effects of lowering $\mathrm{PO}_{2}$ on the hemodynamic and myocardial metabolic recovery for $45 \mathrm{~h}$ after discontinuation of CPB. In addition, we evaluated the effect of infusing diltiazem during reperfusion under $\mathrm{CPB}$.

(Received March 6, 2001; revised manuscript received April 25, 2002; accepted May 13, 2002)

Department of Cardiovascular Surgery, Kinki University School of Medicine, Osaka, Japan

Mailing address: Takehiro Inoue, MD, Department of Cardiovascular Surgery, Kinki University School of Medicine, 377-2 Ohno-Higashi, Osaka-Sayama, Osaka 589-8511, Japan. E-mail: rtc-ryo@med.kindai. ac.jp

\section{Methods}

Patients

The study group comprised 30 consecutive patients undergoing elective coronary artery bypass grafting (CABG) by the same surgeon between January and September 1999. The study was approved by the Institutional Ethics Committee and all patients gave informed consent before inclusion in the study.

Patients were randomly allocated to one of 3 groups based on the $\mathrm{PO}_{2}$ after aortic unclamping during CPB: group $1 \quad(\mathrm{n}=10)$ hyperoxic reperfusion $\left(\mathrm{PO}_{2}=450\right.$ $550 \mathrm{mmHg} ; 490.3 \pm 20.5 \mathrm{mmHg})$; group $2(\mathrm{n}=10)$ : hyperoxic reperfusion $\left(\mathrm{PO}_{2}=450-550 \mathrm{mmHg} ; 497.5 \pm 22.1 \mathrm{mmHg}\right)$ and continuous infusion of diltiazem $(0.5 \mu \mathrm{g} / \mathrm{kg})$; group 3 $(\mathrm{n}=10)$ : lowering reperfusate $\mathrm{PO}_{2}\left(\mathrm{PO}_{2}=200-250 \mathrm{mmHg}\right.$; $219.7 \pm 16.3 \mathrm{mmHg}$ ).

\section{Clinical Management}

Anesthesia was induced with fentanyl $(30-40 \mu \mathrm{g} / \mathrm{kg})$, diazepam $(0.15-0.25 \mu \mathrm{g} / \mathrm{kg})$ and vencuronium bromide $(0.08-0.1 \mathrm{mg} / \mathrm{kg})$, and then maintained with the same drugs. After induction of general anesthesia and systemic application of heparin (300 IU/kg of body weight), CPB (Stockert Instrumente, Munchen, Germany) was initiated in a standard fashion. A hollow fiber membrane oxygenator was used in all cases (Bard HF6000). The extracorporeal circuit was primed with $2,000 \mathrm{ml}$ lactated Ringer's solution and 5,000 U heparin. Nonpulsatile flows of at least $2.0 \mathrm{~L}$. $\mathrm{min}^{-1} \cdot \mathrm{m}^{-2}$ were used at moderate hypothermia (rectal 
Table 1 Patient Characteristics in the 3 Groups of Oxygen Tension

\begin{tabular}{lccc}
\hline \hline & \multicolumn{3}{c}{ Group } \\
\cline { 2 - 4 } & $\begin{array}{c}\text { Hyperoxic reperfusion } \\
(n=10)\end{array}$ & $\begin{array}{c}\text { Hyperoxia }+ \text { diltiazem } \\
(n=10)\end{array}$ & $\begin{array}{c}\text { Lowering PO2 reperfusion } \\
(n=10)\end{array}$ \\
\hline M/F & $6 / 4$ & $5 / 5$ & $6 / 4$ \\
Age (years) & $65.6 \pm 1.7$ & $65.8 \pm 4.2$ & $65.0 \pm 2.2$ \\
BSA $\left(\mathrm{m}^{2}\right)$ & $1.67 \pm 0.12$ & $1.59 \pm 0.09$ & $1.62 \pm 0.19$ \\
Body weight $(\mathrm{kg})$ & $60.0 \pm 2.9$ & $54.5 \pm 3.1$ & $59.5 \pm 5.1$ \\
EF $(\%)$ & $60.2 \pm 11.5$ & $58.5 \pm 10.1$ & $62.2 \pm 10.8$ \\
Coronary disease (2 vessel/3 vessel) & $5 / 5$ & $4 / 6$ & $4 / 6$ \\
No. of bypass & $3.0 \pm 0.3$ & $3.3 \pm 0.2$ & $3.1 \pm 0.3$ \\
Aortic clamp time (min) & $70.8 \pm 10.4$ & $76.6 \pm 4.7$ & $68.0 \pm 11.8$ \\
CPB time (min) & $152.1 \pm 20.8$ & $159.1 \pm 12.0$ & $156.6 \pm 9.6$
\end{tabular}

Values are mean \pm standard error of the mean. BSA, body surface area; $E F$, ejection fraction; $C P B$, cardiopulmoanary bypass.

CI

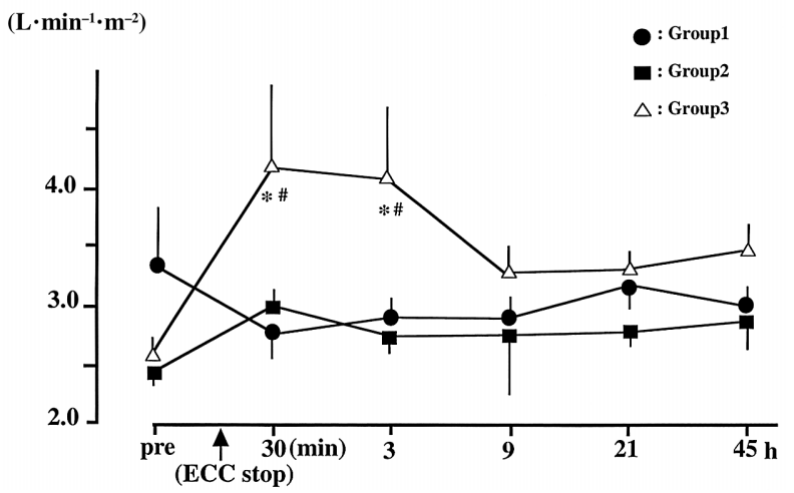

Fig 1. Cardiac index (CI) before starting the surgical procedure and at $30 \mathrm{~min}, 3,9,21$, and $45 \mathrm{~h}$ after discontinuation of cardiopulmonary bypass. Group 1: hyperoxic reperfusion (oxygen tension $=450$ $550 \mathrm{mmHg}$ ); Group 2: hyperoxic reperfusion + diltiazem; Group 3: reduced $\mathrm{PO}_{2}$ reperfusion (oxygen tension $=200-250 \mathrm{mmHg}$ ). ${ }^{*} \mathrm{p}<0.05$ vs hyperoxic reperfusion group, $* \mathrm{p}<0.05$ vs diltiazem + hyperoxic reperfusion group.

temperature $28-30^{\circ} \mathrm{C}$ ) and did not fall below $2.2 \mathrm{~L} \cdot \mathrm{min}^{-1}$. $\mathrm{m}^{-2}$ during CPB. The coronary sinus was cannulated (Baxter Healthcare Corporation, UT, USA) and antegrade and/or retrograde blood cardioplegia $\left(\mathrm{pH} 7.8 ; \mathrm{K}^{+}\right.$, $20 \mathrm{mmol} / \mathrm{L} \mathrm{Na}^{+}, 135 \mathrm{mmol} / \mathrm{L} ; \mathrm{Ca}^{2+}, 0.5 \mathrm{mmol} / \mathrm{L}$; Mannitol, $21.4 \mathrm{mmol} / \mathrm{L}$ ) was administered using the same technique in all 3 groups. The actual final composition of the blood cardioplegia was: $\mathrm{pH} 7.837 \pm 0.26 ; \mathrm{K}^{+}, 20.9 \pm 0.7 \mathrm{mmol} / \mathrm{L}$; $\left.\mathrm{Na}^{+}, 125.8 \pm 5.1 \mathrm{mmol} / \mathrm{L} ; \mathrm{Ca}^{2+}, 0.5 \pm 0.1 \mathrm{mmol} / \mathrm{L}\right)$. No significant differences in the hemoglobin concentration $(\mathrm{Hb}$, $6.1 \pm 0.2 \mathrm{~g} / \mathrm{dl})$ or $\mathrm{PO}_{2}(234.5 \pm 10.7 \mathrm{mmHg})$ of the blood cardioplegia were observed among the 3 groups.

CABG was performed with a standard nonpulsatile CPB technique, with moderate hypothermia and hemodilution (hematocrit, 20-25\%). Cardiac arrest was induced with antegrade administration $(3 \mathrm{ml} / \mathrm{kg})$ of cold $\left(4^{\circ} \mathrm{C}\right)$ Young's solution and followed by infusion of conventional blood cardioplegic solution every $20 \mathrm{~min}$ at $10 \mathrm{ml} / \mathrm{kg}$.

After aortic unclamping, the $\mathrm{PO}_{2}$ on $\mathrm{CPB}$ was controlled by changing oxygen delivery and monitored continuously using a blood gas monitor (CDI model 400; $3 \mathrm{M}$ Health Care; Tustin, USA). Until the rectal temperature was at least $35^{\circ} \mathrm{C}$, the perfusion pressure on $\mathrm{CPB}$ was maintained at $50-60 \mathrm{mmHg}$ for almost $20 \mathrm{~min}$ after aortic unclamping. Weaning from CPB was done after the patient had been warmed and $\mathrm{CPB}$ was discontinued with protamine for

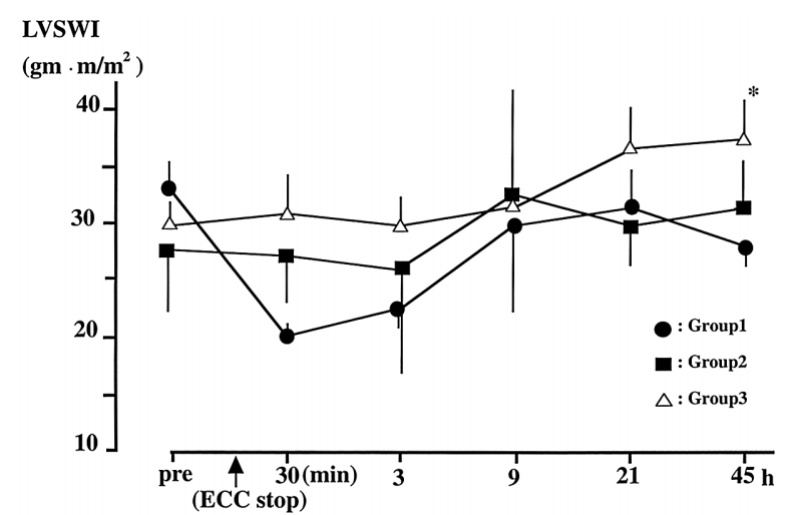

Fig 2. Left ventricular stroke work index (LVSWI) before starting the surgical procedure and at $30 \mathrm{~min}, 3,9,21$, and $45 \mathrm{~h}$ after discontinuation of cardiopulmonary bypass. Group 1: hyperoxic reperfusion (oxygen tension $=450-550 \mathrm{mmHg}$ ); Group 2: hyperoxic reperfusion + diltiazem; Group 3: reduced $\mathrm{PO}_{2}$ reperfusion (oxygen tension= 200-250 $\mathrm{mmHg}$ ).

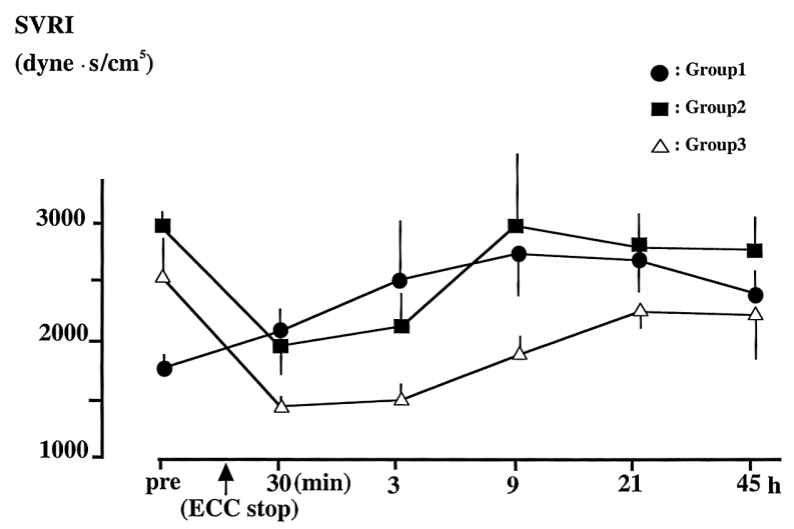

Fig 3. Systemic vascular resistance index (SVRI) before starting the surgical procedure and at $30 \mathrm{~min}, 3,9,21$, and $45 \mathrm{~h}$ after discontinuation of cardiopulmonary bypass. Group 1: hyperoxic reperfusion (oxygen tension $=450-550 \mathrm{mmHg}$ ); Group 2: hyperoxic reperfusion + diltiazem; Group 3: reduced $\mathrm{PO}_{2}$ reperfusion (oxygen tension= $200-250 \mathrm{mmHg}$ ).

heparin reversal.

\section{Hemodynamic Study}

Before the operation, a radial artery catheter and a SwanGanz pulmonary artery catheter (Baxter Healthcare Corp, 


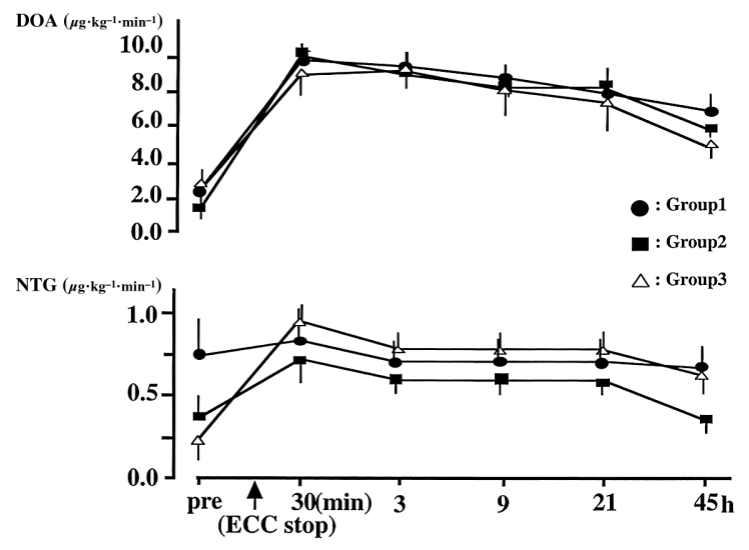

Fig 4. Dopamine (DOA) and nitroglycerin (NTG) doses before the starting surgical procedure and at $30 \mathrm{~min}, 3,9,21$, and $45 \mathrm{~h}$ after discontinuation of cardiopulmonary bypass. Group 1: hyperoxic reperfusion (oxygen tension $=450-550 \mathrm{mmHg}$ ); Group 2: hyperoxic reperfusion+diltiazem; Group 3: reduced $\mathrm{PO}_{2}$ reperfusion (oxygen tension $=200-250 \mathrm{mmHg}$ ).

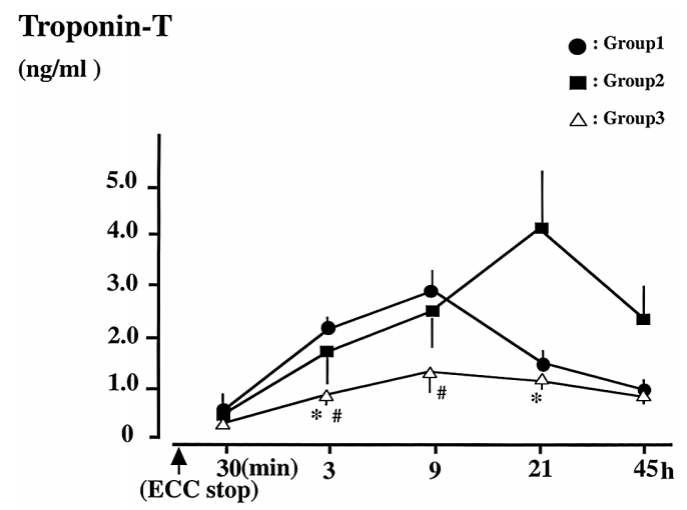

Fig 6. Troponin-T concentration before starting the surgical procedure and at $30 \mathrm{~min}, 3,9,21$, and $45 \mathrm{~h}$ after discontinuation of cardiopulmonary bypass. Group 1: hyperoxic reperfusion (oxygen tension $=450-550 \mathrm{mmHg}$ ); Group 2: hyperoxic reperfusion + diltiazem; Group 3: reduced $\mathrm{PO}_{2}$ reperfusion (oxygen tension $=$ $200-250 \mathrm{mmHg}$ ). ${ }^{*} \mathrm{p}<0.05$ vs hyperoxic reperfusion group, ${ }^{*} \mathrm{p}<0.05$ vs diltiazem +hyperoxic reperfusion group.

Edwards Division, Santa Ana, CA, USA) were inserted for continuous monitoring of systemic and pulmonary artery pressures for measuring cardiac output (CO) and pulmonary capillary wedge pressure (PCWP). Hemodynamic measurements were taken at 6 preset times: before starting the surgical procedure and at $30 \mathrm{~min}$ and $3,9,21$, and $45 \mathrm{~h}$ after discontinuation of CPB. Arterial pressure (AP) and central venous pressure (CVP) were measured continuously. $\mathrm{CO}$ was determined by the thermodilution technique and PCWP was measured immediately before each $\mathrm{CO}$ measurement. Systemic vascular resistance index (SVRI) was calculated with the formula: SVRI (dyne $\left.\cdot \mathrm{s} / \mathrm{cm}^{5}\right)=80 \times$ mean AP ((MAP) $-\mathrm{CVP}) /$ cardiac index $(\mathrm{CI})$. The left ventricular stroke work index (LVSWI) was calculated according to the formula: LVSWI $\left(\mathrm{gm} \cdot \mathrm{m}^{-2} \cdot\right.$ beat $\left.^{-1}\right)=13.6 \times\left(\mathrm{CI} /\right.$ heart $^{2}$ rate $(\mathrm{HR})) \times(\mathrm{MAP}-\mathrm{PCWP})$. Postoperative preload and afterload were optimized by assistants who were unaware of the cardioplegic technique used.

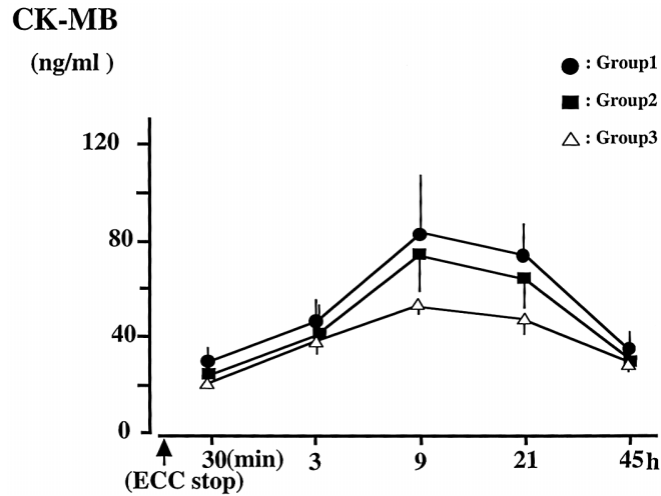

Fig 5. Creatine phosphokinase-MB (CPK-MB) concentration before starting the surgical procedure and at $30 \mathrm{~min}, 3,9,21$, and $45 \mathrm{~h}$ after discontinuation of cardiopulmonary bypass. Group 1: hyperoxic reperfusion (oxygen tension $=450-550 \mathrm{mmHg}$ ); Group 2: hyperoxic reperfusion+diltiazem; Group 3: reduced $\mathrm{PO}_{2}$ reperfusion (oxygen tension $=200-250 \mathrm{mmHg}$ ).

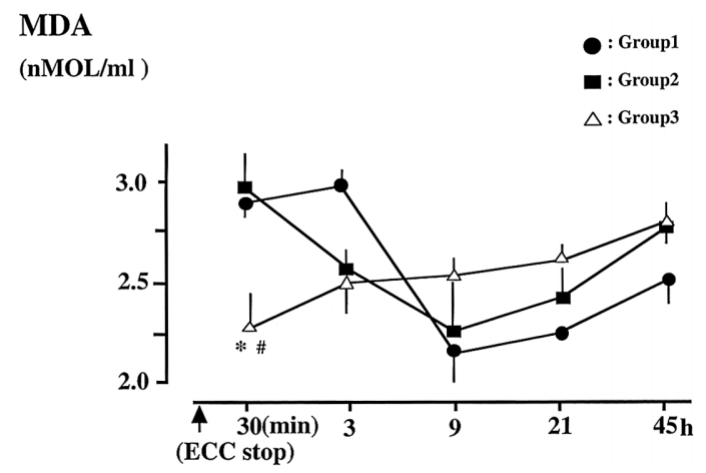

Fig 7. Malondialdehyde (MDA) concentration before starting the surgical procedure and at $30 \mathrm{~min}, 3,9,21$, and $45 \mathrm{~h}$ after discontinuation of cardiopulmonary bypass. Group 1: hyperoxic reperfusion (oxygen tension $=450-550 \mathrm{mmHg}$ ); Group 2: hyperoxic reperfusion + diltiazem; Group 3: reduced $\mathrm{PO}_{2}$ reperfusion (oxygen tension= $200-250 \mathrm{mmHg}$ ). ${ }^{*} \mathrm{p}<0.05$ vs hyperoxic reperfusion group, ${ }^{*} \mathrm{p}<0.05$ vs diltiazem + hyperoxic reperfusion group.

\section{Blood Samples and Measurements}

Arterial and venous samples were assayed to estimate the myocardial release of creatine kinase $(\mathrm{CK})$, lactate, lactate dehydrogenase (LDH-1, LDH-2), troponin-T and malondialdehyde at $30 \mathrm{~min}$ and $3,9,21$, and $45 \mathrm{~h}$ after discontinuation of CPB. The blood concentration of CK was measured by a UV method, lactate and LDH by enzymatic methods, and troponin-T by an enzyme immunoassay method.

\section{Statistical Analysis}

Group data are expressed as mean \pm standard deviation. A statistical analysis was performed using a one-way ANOVA. When significant differences were detected, pairwise comparisons were made using the Scheffe F test. Statistical significance was assumed at $\mathrm{p}<0.05$.

\section{Results}

The clinical characteristics of patients are summarized in 
Table 1; there were no significant differences between the groups.

\section{Pre- and Postoperative Cardiac Function}

Before the surgical procedure began, there were no significant differences in the hemodynamics of the 3 groups nor did they differ in preoperative ejection fraction on left ventricular angiography. Additionally, all groups received the same preoperative medications, such as nitrate and anticoagulants. At $30 \mathrm{~min}$ and $3 \mathrm{~h}$ after discontinuation of $\mathrm{CPB}$, the $\mathrm{CI}$ in group 3 was significantly higher than in groups 1 and 2 , but at $9 \mathrm{~h}$ after discontinuation of $\mathrm{CPB}$, no significant difference was observed among the 3 groups. No significant difference in CI was found between groups 1 and 2 before or after discontinuation of CPB. The absolute values are shown in Fig 1.

At $30 \mathrm{~min}$ and $3 \mathrm{~h}$ after discontinuation of $\mathrm{CPB}$, the LVSWI in group 3 tended to be higher than in groups 1 and 2 (Fig 2). At $30 \mathrm{~min}$ and 3, 21, and $9 \mathrm{~h}$ after discontinuation of $\mathrm{CPB}$, the SVRI in group 3 tended to be lower than in groups 1 and 2 (Fig 3 ).

No significant differences in systolic aortic pressure, PCWP, and CVP were found among the 3 groups.

\section{Pre- and Postoperative Doses of Infused Dopamine (DOA) and Nitroglycerin (NTG)}

The doses of DOA before the surgical procedure and after discontinuation of CPB did not differ significantly nor was there a significant difference in the dose of NTG among the groups (Fig 4).

\section{Pre-and Postoperative Biochemistry}

After discontinuation of $\mathrm{CPB}$, there were no significant differences in the CK, LDH-1, LDH-2 and lactate concentrations among the 3 groups. Although there was not a significant difference in the CK-MB concentration among the 3 groups, it tended to be lower in group 3 than in groups 1 and 2 (Fig 5). The troponin-T concentration in group 3 was significantly lower than in groups 1 and 2 at $3 \mathrm{~h}$ after discontinuation of CPB (Fig 6), and was also significantly lower than in groups 1 and 2 at $9 \mathrm{~h}$ and $21 \mathrm{~h}$, respectively, after discontinuation of CPB.

The malondialdehyde concentration in group 3 was significantly lower than in groups 1 and 2 at 30 min after discontinuation of CPB (Fig 7).

\section{Discussion}

The concept of reperfusion injury remains controversial with several proposed mechanisms, but it is mainly oxygen-derived free radicals and calcium overload that play an important role in the development of left ventricular dysfunction, stunning, reperfusion arrhythmias, vascular damage, and endothelial dysfunction?2,3,12,13

During adult cardiac surgery, CPB is commonly hyperoxic fashion and CPB can itself also lead to the production of oxygen-derived free radicals!,14 The cell protects itself by ubiquitous endogenous free radical scavengers, which may be depleted by ischemia and additionally overwhelmed by the burst of free radical production that occurs with the onset of reoxygenation or hyperoxia after reperfusion with aortic unclamping during CPB 15 Prasad et al have shown that superoxide dismutase and catalase, which are scavengers of superoxide anion and hydrogen peroxide, respectively, are effective in preventing postpump cardiac dysfunction ${ }^{14}$ and $\mathrm{Ku}$ et al have reported that the hydroxyl radical scavenger, nicaraven, improves the recovery of cardiac function following preservation and reperfusion! 16

The present study showed that lowering the reperfusate $\mathrm{PO}_{2}$ after aortic unclamping on $\mathrm{CPB}$ reduced oxidative myocardial damage and the effects on the hemodynamics and myocardial enzyme release persisted for approximately $3 \mathrm{~h}$ after discontinuation of CPB. In fact, the CI in the lowering reperfusate $\mathrm{PO}_{2}$ group was higher than in the hyperoxic reperfusion groups at $30 \mathrm{~min}$ and $3 \mathrm{~h}$ after discontinuation of CPB. Additionally, malondialdehyde and troponin- $T$ concentrations were significantly lower at $30 \mathrm{~min}$ and $3 \mathrm{~h}$, respectively, after $\mathrm{CPB}$ in the lowering reperfusate $\mathrm{PO}_{2}$ group compared with the hyperoxic reperfusion groups.

It has been shown that the myocardial damage that occurs with reoxygenation depends on the oxygen tension, and that lowering oxygen tension will result in reduced creatine kinase release6 In the present study, the CK-MB concentration in the lowering reperfusate $\mathrm{PO}_{2}$ group tended to be lower after discontinuation of CPB than in the hyperoxic reperfusion group. Lowering the $\mathrm{PO}_{2}$ reperfusion during $\mathrm{CPB}$ may avoid the deleterious reoxygenation process that leads to a burst of free radicals. ${ }^{17,18}$ Ihnken reports that normoxic $\mathrm{CPB}$ in the hypoxic immature heart reduces reoxygenation injury and improves myocardial function, ${ }^{18}$ and the benefits of normoxic CPB have been seen in adult normoxic hearts also. We reported recently that maintaining a more physiologic $\mathrm{PO}_{2}$ during reperfusion following ischemia attenuates reperfusion injury 19

The mechanism of reperfusion injury is, in part, attributed to calcium overload ${ }^{2,3}$ and there is experimental evidence of calcium pump dysfunction in reperfusion injury, 3,20 Although calcium antagonists were initially designed as antianginal agents, they were found to preserve the ischemic myocardium ${ }^{8,9}$ and have been tested extensively in regard to myocardial protection. Diltiazem is a calcium antagonist that has a potent cardioprotective effect during reperfusion at low doses and in a dose-dependent fashion, 810 However, Dagenasis et al reported that diltiazem is less effective in improving both coronary vasodilatation and left ventricular hemodynamics? ${ }^{2}$ Clinical studies have investigated the beneficial effects of adding calcium antagonists to cardioplegic solutions to optimize cardiac preservation during open heart surgery and Christakis et al in particular found reduced ischemic injury after the addition of diltiazem to the cardioplegia during elective coronary bypass ${ }^{2}$

In addition, calcium antagonists have been implicated as antioxidants. Noronhata-Dutra et al reported that calcium antagonist pretreatment prevented in vivo generation of free radicals by adrenaline, ${ }^{23}$ and Obata et al demonstrated that diltiazem suppressed hydroxyl free radical generation by ischemic reperfusion in the rat heart24 Therefore, diltiazem may suppress free radical generation and thus prevent the myocardial ischemic injury associated with generation of free radicals, directly or indirectly. Diltiazem acts during ischemic reperfusion as a calcium channel blocker predominantly and decreases calcium overload, but the precise mechanism is unclear and requires further research.

In the present clinical study, the patients were divided into 3 subgroups to determine whether, in comparison with diltiazem infusion, lowering the oxygen tension would reduce the reperfusion injury in the early period after cardiac surgery. The diltiazem dosage conformed to previ- 
ous studies, ${ }^{10,22}$ but we did not find a significant difference in $\mathrm{CI}$ between the hyperoxic $\mathrm{PO}_{2}+$ diltiazem group and the hyperoxic $\mathrm{PO}_{2}$ group. Further studies are needed in this regard. Additionally, the $\mathrm{CI}$ in the lowering reperfusate $\mathrm{PO}_{2}$ group was higher than in the hyperoxic $\mathrm{PO}_{2}+$ diltiazem group at $30 \mathrm{~min}$ and $3 \mathrm{~h}$ after discontinuation of CPB. Likewise, the malondialdehyde concentration in the lowering reperfusate $\mathrm{PO}_{2}$ group was less than in the hyperoxic $\mathrm{PO}_{2}+$ diltiazem group at 30 min after discontinuation of CPB. Reduction of oxygen tension may have more effect on postpump myocardial performance than calcium antagonists for several hours after CPB and because it is easy to control oxygen delivery on $\mathrm{CPB}$, this technique is convenient and safe.

\section{Study Limitations}

We documented short-term results, but for complete understanding of the oxidative reperfusion injury in adult heart surgery, the long-term effects of oxidative reperfusion damage have to be studied. In the present study, the patients were divided into 2 groups according to the $\mathrm{PO}_{2}$ level, but for more detailed data, there should be several groups with other oxygen tension levels. Additionally, there is a potential discrepancy in the relationship between the oxygen concentration achieved by lowering $\mathrm{PO}_{2}$ on CPB and the cardioprotective effects, including the limitation of the lipid peroxidation. It may be a limitation of the present clinical study and further study, for example using free radical scavenging drugs, is needed.

\section{Conclusion}

Lowering the reperfusate $\mathrm{PO}_{2}$ after aortic unclamping on $\mathrm{CPB}$ was more effective in reducing reperfusion injury than a calcium antagonist in the short term, and in the severely compromised heart, lowering the $\mathrm{PO}_{2}$ on $\mathrm{CPB}$ may potentially reduce morbidity and mortality. Although $\mathrm{CPB}$ is commonly hyperoxic, the present results support our hypothesis that a reduced oxygen tension during reperfusion after aortic unclamping on $\mathrm{CPB}$ can reduce oxidative myocardial damage.

\section{References}

1. Cavarocchi NC, England MD, Schaff H, Russo P, Orszulak TA, Schnell WA, et al. Oxygen free radical generation during cardiopulmonary bypass: Correlation with complement activation. Circulation 1986; 74(Suppl): III130-III133.

2. Miyamae M, Camacho A, Weiner MW. Attenuation of postischemic reperfusion injury is related to prevention of $\left[\mathrm{Ca}^{2+}\right] \mathrm{m}$ overload in rat hearts. Am J Physiol 1996; 271: H2145-H2153.

3. Mochizuki S, Jiang C. $\mathrm{Na}^{+} / \mathrm{Ca}^{++}$exchanger and myocardial ischemia/ reperfusion. Jpn Heart J 1998; 39: 707-714.

4. Littauer A, De Groot H. Release of reactive oxygen by hepatocytes on reoxygenation: Three phases and role of mitochondria. Am $J$ Physiol 1992; 262: G1015-G1020.

5. Ihnken K, Morita K, Buckberg GD. Studies of hypoxemic/reoxy- genation injury: With aortic clamping. XI. Cardiac advantages of normoxemic versus hyperoxemic management during cardiopulmonary bypass. J Thorac Cardiovasc Surg 1995; 110: 1255-1264.

6. Hearse DJ, Humphrey SM, Bullock GR. The oxygen paradox and the calcium paradox: Two facets of the same problem. J Mol Cell Cardiol 1987; 10: 641-668.

7. Ihnken K, Winkler A, Schlensak C, Sarai K, Neidhart G, Unkelbach $\mathrm{U}$, et al. Normoxic cardiopulmonary bypass reduces oxidative myocardial damage and nitric oxid during cardiac operations in the adult. J Thorac Cardiovasc Surg 1998; 116: 327-334.

8. Becker BF, Mobert J. Low-dose calcium antagonists reduce energy demand and cellular damage of isolated hearts during both ischemia and reperfusion. Naunyn Schmiedebergs Arch Pharmacol 1999; 360: 287-294.

9. Seitelberger R, Zwolfer W, Huber S, Schwarzacher S, Binder TM, Peschl F, et al. Nifedipine reduces the incidence of myocardial infarction and transient ischemia in patients undergoing coronary bypass grafting. Circulation 1991; 83: 460-468.

10. Herzog WR, Vogel RA, Schlossberg ML, Edenbaum LR, Scott HJ, Serebruany VL. Short-term low dose intracoronary diltiazem administered at the onset of reperfusion reduces myocardial infarct size. Int J Cardiol 1997; 59: 21 -27.

11. Gambelli G, Donati R, Mezzanotte R, Pozzar F, Cesario AS, Schiavo $\mathrm{B}$, et al. Improvement of postinfarct left myocardial contractile function after administration of diltiazem. G Ital Cardiol 1998; 28: 249258.

12. Opie LH. Reperfusion injury and its pharmacologic modification. Circulation 1989; 80: 1049-1062.

13. Kukreja RC, Janin Y. Reperfusion injury: Basic concepts and protection strategies. J Thromb Thrombolysis 1997; 4: 7-24.

14. Prasad K, Chan WP, Bharadwaj B. Superoxide dismutase and catalase in protection of cardiopulmonary bypass-induced cardiac dysfunction and cellular injury. Can J Cardiol 1996; 12: $1083-$ 1091.

15. Dhaliwai H, Kirshenbaum LA, Randhawa AK, Singal PK. Correlation between antioxidant changes during hypoxia and recovery on reoxygenation. Am J Physiol 1991; 261: H632-H638.

16. Ku K, Kin S, Hashimoto M, Saitoh Y, Nosawa S, Iwasaki S, et al. The role of a hydroxyl radical scavenger (nicaraven) in recovery of cardiac function following preservation and reperfusion. Transplantation 1996; 62: 1090-1095.

17. Ihnken K, Morita K, Buckberg GD, Winkelmann B, Beyersdorf F, Sherman MP. Reduced oxygen tension during cardiopulmonary bypass limits myocardial damage in acute hypoxic immature piglet hearts. Eur J Cardiothorac Surg 1996; 10: 1127-1134; Discussion 1135 .

18. Ihnken K. Myocardial protection in hypoxic immature hearts. Thorac Cardiovasc Surg 2000; 48: 46-54.

19. Kaneda T, Ku K, Inoue T, Onoe M, Oku H. Postischemic reperfusion injury can be attenuated oxygen tension control. Jpn Circ J 2001; 65: 213-218.

20. Smart SC, Sagar KB, el Schultz J, Warltier DC, Jones LR. Injury to the $\mathrm{Ca}^{2+}$ ATPase of the sarcoplasmic reticulum in anesthetized dogs contributes to myocardial reperfusion injury. Cardiovasc Res 1997; 36: $174-184$.

21. Dagenais F, Cartier R, Hollmann C, Buluran J. Calcium-channel blockers preserve coronary endothelial reactivity after ischemiareperfusion. Ann Thorac Surg 1997; 63: 1050-1056.

22. Christakis GT, Fremes SE, Weisel RD, Tittley JG, Mickle DA, Ivanov J, et al. Diltiazem cardioplegia: A balance of risk and benefits. J Thorac Cardiovasc Surg 1986; 91: 647-661.

23. Noronha-Dutra A, Steen-Dutra EM, Wooif N. An antioxidant role for calcium antagonists in the prevention of adrenaline mediated myocardial and endothelial damage. Br Heart J 1991; 65: 322-325.

24. Obata T, Yamanaka Y. Protective effect of diltiazem on myocardial ischemic injury associated with $\mathrm{OH}$ generation. Comp Biochem Physiol A Physiol 1997; 117: 257-261. 